\title{
Evaluating of the association between $A B O$ blood groups and coronavirus disease 2019 (COVID-19) in Iraqi patients
}

\author{
Ali H. Ad'hiah ${ }^{1 *}$ (D), Risala H. Allami ${ }^{2}$, Raghdan H. Mohsin ${ }^{3}$, Maha H. Abdullah², Ali J. R. AL-Sa'ady ${ }^{4}$ and \\ Mustafa Y. Alsudani ${ }^{5}$
}

\begin{abstract}
Background: Susceptibility to the pandemic coronavirus disease 2019 (COVID-19) has recently been associated with $\mathrm{ABO}$ blood groups in patients of different ethnicities. This study sought to understand the genetic association of this polymorphic system with risk of disease in Iraqi patients. Two outcomes of COVID-19, recovery and death, were also explored. ABO blood groups were determined in 300 hospitalized COVID-19 Iraqi patients (159 under therapy, 104 recovered, and 37 deceased) and 595 healthy blood donors. The detection kit for 2019 novel coronavirus (2019-nCoV) RNA (PCR-Fluorescence Probing) was used in the diagnosis of disease.
\end{abstract}

Results: Mean age was significantly increased in patients compared to controls ( $49.8 \pm 11.7$ vs. $28.9 \pm 6.6$ years; $p<$ 0.001). A similar observation was made in recovered ( $42.1 \pm 10.4$ vs. $28.9 \pm 6.6$ years; $p<0.001)$ and deceased (53.6 \pm 9.7 vs. $28.9 \pm 6.6$ years; $p<0.001)$ cases. The mean age was also significantly increased in deceased cases compared to recovered cases $(53.6 \pm 9.7$ vs. $42.1 \pm 10.4$ years; $p<0.001)$. There were gender-dependent differences in COVID-19 prevalence. The percentage of COVID-19 was higher in males than in females (all cases: 59.7 vs. 40.3\%; recovered cases: 55.8 vs. 44.2\%). Such male-gender preponderance was more pronounced in deceased cases (67.6 vs. 32.4\%). Logistic regression analysis revealed that groups $A B$ and $B+A B$ were significantly associated with increased risk to develop COVID-19 $(\mathrm{OR}=3.10 ; 95 \% \mathrm{Cl} 1.59-6.05 ; p C=0.007$ and $\mathrm{OR}=2.16 ; 95 \% \mathrm{Cl} 1.28-3.63 ; p C=$

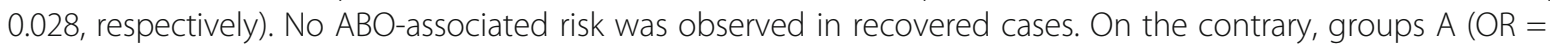
$14.60 ; 95 \% \mathrm{Cl} 2.85-74.88 ; p C=0.007), A B(O R=12.92 ; 95 \% C l 2.11-79.29 ; p C=0.042), A+A B(O R=14.67 ; 95 \% C l$ 2.98-72.33; $p C=0.007)$, and $A+B+A B(O R=9.67 ; 95 \% C l$ 2.02-46.24; $p C=0.035)$ were associated with increased risk of death in deceased cases.

Conclusions: The findings of this study suggest that group AB may be a susceptibility biomarker for COVID-19, while group A may be associated with increased risk of death.

Keywords: COVID-19, ABO blood group, Age, Gender

\section{Background}

Severe acute respiratory syndrome coronavirus 2 (SARS$\mathrm{CoV}-2$ ) is the strain of coronavirus that causes coronavirus disease 2019 (COVID-19) [1]. Since the emergence

\footnotetext{
*Correspondence: dr.a.h.adhiah@gmail.com;

dr.ahadhiah@sc.uobaghdad.edu.iq

'Tropical-Biological Research Unit, College of Science, University of Baghdad, Baghdad, Iraq

Full list of author information is available at the end of the article
}

of the first case of COVID-19 in December 2019 (Wuhan, China), the infection has become pandemic spreading to more than 300 nations. Up to the fifth of June $2020,11,241,655$ total cases have been reported with a mortality rate of $4.7 \%$ (total deaths $=530,668$ cases). The corresponding figures for Iraq were 58,354 and 4.1\% (total deaths $=2368$ ), respectively [2]. Up-to-date, there has been no effective therapy or vaccine. Further, there has been no specific biomarker for the disease. Risk 
factors that have been determined were mostly related to general clinical observations; for instance, age, gender, and chronic diseases [3]. However, ABO blood groups have been recently introduced as a genetic system that may influence susceptibility to COVID-19 [4, 5].

The ABO blood group antigens are cell-surface glycoproteins present principally on erythrocytes and on a variety of other cell lines and tissues. They are indirectly encoded by a single locus on chromosome 9 (9q34.1q34.2) [6]. At the ABO locus, two codominant functional alleles encode blood group $\mathrm{A}$ and $\mathrm{B}$ transferases $(A$ and $B$ alleles, respectively). A third recessive $O$ allele encodes enzymatically inactive proteins that have no activity of either of the transferases. Accordingly, four basic $\mathrm{ABO}$ phenotypes are recognized; $\mathrm{A}, \mathrm{B}, \mathrm{AB}$, and $\mathrm{O}$ [7]. $\mathrm{ABO}$ alleles and phenotypes are frequent targets for epidemiological and anthropological studies because they are genetically determined traits, and their polymorphic expression is documented among populations so far investigated. Frequency of these alleles and phenotypes is race-dependent and the major racial populations (Caucasians, Orientals, and Negros) show great variations [8]. Further, different disease-association studies have disclosed the significance of ABO blood groups as genetic risk factors for different human diseases (viral, bacterial, fungal, parasitic, and malignant diseases) [9].

With respect to COVID-19, recent studies have associated $\mathrm{ABO}$ blood groups with susceptibility to disease. In these studies, group $\mathrm{A}, \mathrm{B}$, or $\mathrm{AB}$ was suggested to act as a risk factor for the infection, while group $\mathrm{O}$ was associated with a decreased risk in most populations investigated $[4,5,10]$. Before that, an epidemiological study was conducted during the SARS-CoV outbreak (20022003) on hospital workers who contracted the infection. The analysis revealed that workers with group $\mathrm{O}$ were less likely to become infected with SARS-CoV compared to non-O workers [11].

In line with these finding, the present preliminary study sought to understand the genetic association of ABO blood groups with susceptibility to COVID-19 in Iraqi patients. Two outcomes of the disease, recovery and death, were also explored in this context. To the best of our knowledge, this is the first study in Iraqi patients.

\section{Methods}

\section{Populations studied}

During June 2020, a case-control study was conducted after obtaining the participants written informed consent and approval of the Ethics Committee at the Iraqi Ministry of Health and Environment (N268 on 31 May 2020). Three hundred cases were recruited from hospitals in Baghdad; 159 under therapy, 104 recovered, and 37 deceased cases. Upon admission to hospital (24-72 h), nasal swabs of patients were examined using the detection kit for 2019 novel coronavirus (2019-nCoV) RNA (PCR-Fluorescence Probing) following instructions of manufacturer (Da An Gene Co., Ltd. of Sun Yat-sen University, China). Enrolled patients were those admitted to the hospitals with symptoms suggestive of COVID-19 and had laboratory-confirmed infection as determined by the aforementioned kit (inclusion criteria). Patients with suspected COVID-19 and were negative for the test were excluded from the study. A control sample of 595 individual (potential blood donors) were also included in the study, and their serum profile for anti-virus antibodies was negative (Central Blood Bank, Baghdad). Age and gender distributions of patients and controls are given in Figs. 1 and 2 and Table 1.

\section{Statistical analysis}

$\mathrm{ABO}$ blood group alleles and phenotypes were given as numbers and percentage frequencies. Estimation of allele frequencies and Hardy-Weinberg equilibrium (HWE) testing were carried out using the software S2 ABOestimator (http://webpages.fc.ul.pt/ pjins/Soft/ABOestimator). Logistic regression analysis (adjusted for age and gender) was employed to assess the genetic association of $\mathrm{ABO}$ blood group with COVID-19 infection. It was expressed as odds ratio (OR) and $95 \%$ confidence interval (CI). The least significant difference (LSD) or Duncan multiple range test assessed the significant differences between ages, which were given as mean \pm standard deviation (SD). A probability $(p)$-value $\leq 0.05$ was considered statistically significant after applying Bonferroni correction $(p c)$. The statistical package IBM SPSS Statistics 25.0 (Armonk, NY: IBM Corp.) was used to carry out these analyses.

\section{Results \\ Age and gender}

Mean age was significantly increased in COVID-19 cases compared to controls $(49.8 \pm 11.7$ vs. $28.9 \pm 6.6$ years; $p$ $<0.001)$. A similar observation was made in recovered $(42.1 \pm 10.4$ vs. $28.9 \pm 6.6$ years; $p<0.001)$ and deceased $(53.6 \pm 9.7$ vs. $28.9 \pm 6.6$ years; $p<0.001)$ cases. The mean age was also significantly increased in deceased cases compared to recovered cases $(53.6 \pm 9.7$ vs. $42.1 \pm$ 10.4 years; $p<0.001$ ) (Fig. 2). There were genderdependent differences in the disease prevalence. The percentage of COVID-19 was higher in males than in females (all cases 59.7 vs. $40.3 \%$; recovered cases 55.8 vs. $44.2 \%)$. Such male-gender preponderance was more pronounced in deceased cases (67.6 vs. 32.4\%). However, the mean age showed no significant variation between males and females in each group of patients or controls (Table 1). 


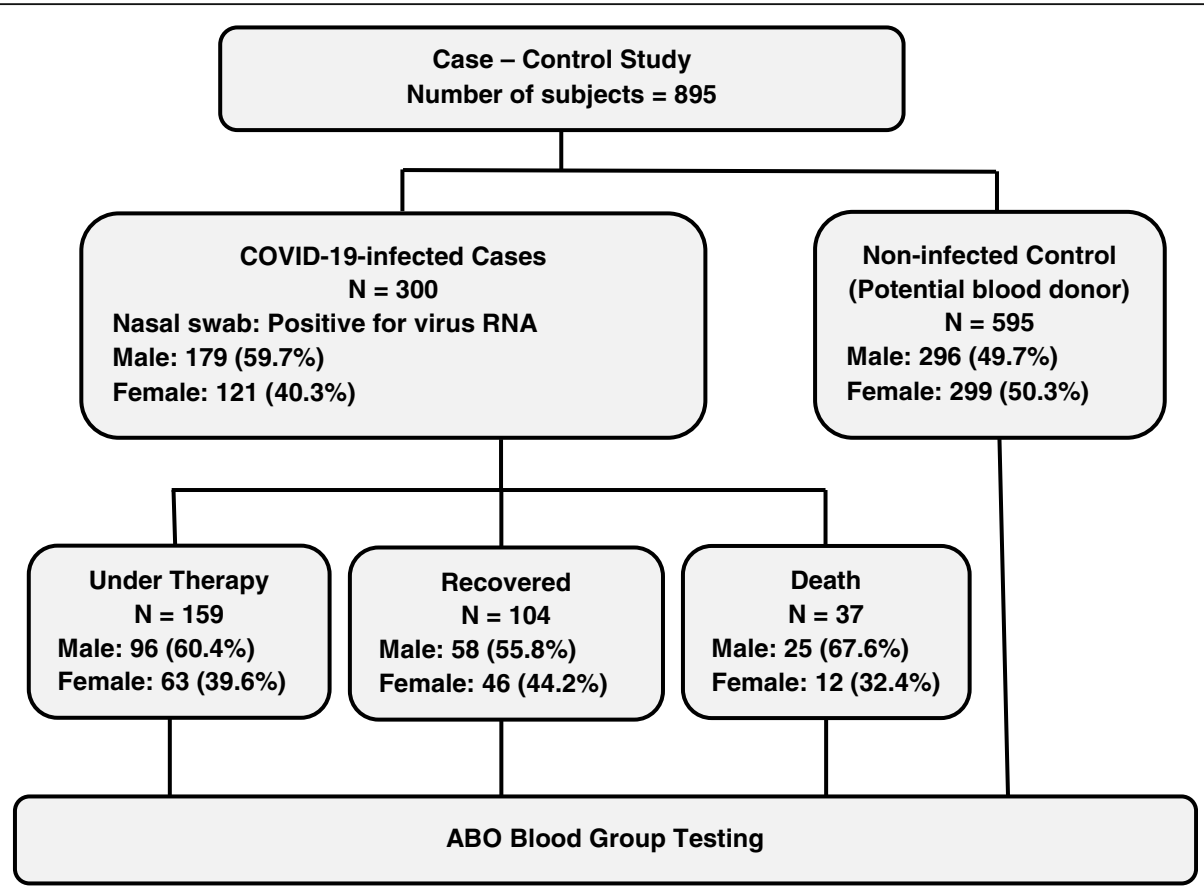

Fig. 1 Flowchart showing experimental design of study

\section{$A B O$ phenotypes and alleles}

Frequencies of $\mathrm{A}, \mathrm{B}, \mathrm{AB}$, and $\mathrm{O}$ blood group phenotypes showed significant variations between COVID-19 patients (all cases, recovered, and deceased) and controls $\left(p c\right.$ value $=8.8 \times 10^{-4}, 0.012$ and $1.5 \times 10^{-6}$, respectively $)$ (Table 2). Estimating ABO allele frequencies revealed that $r[\mathrm{O}]$ was the most frequent allele in controls (allele frequency $=0.577$ ). It was also most frequently encountered in all and recovered cases, but with a lower frequency compared to controls (0.465 and 0.526 vs. 0.577 , respectively). Such profile was different in deceased cases, and $p[\mathrm{~A}]$ was the most frequent allele (allele frequency $=0.601)($ Table 3$)$.

\section{Logistic regression analysis}

Logistic regression analysis revealed that groups $\mathrm{AB}$ and $\mathrm{B}+\mathrm{AB}$ versus groups $\mathrm{O}$ (reference category) were associated with a significantly increased risk to develop COVID-19 $(\mathrm{OR}=3.10 ; 95 \%$ CI $1.59-6.05 ; p c$ value = 0.007 and $\mathrm{OR}=2.16 ; 95 \%$ CI $1.28-3.63 ; p c$ value $=$ 0.028 , respectively). No $\mathrm{ABO}$-associated risk was observed in recovered cases. However, a significantly

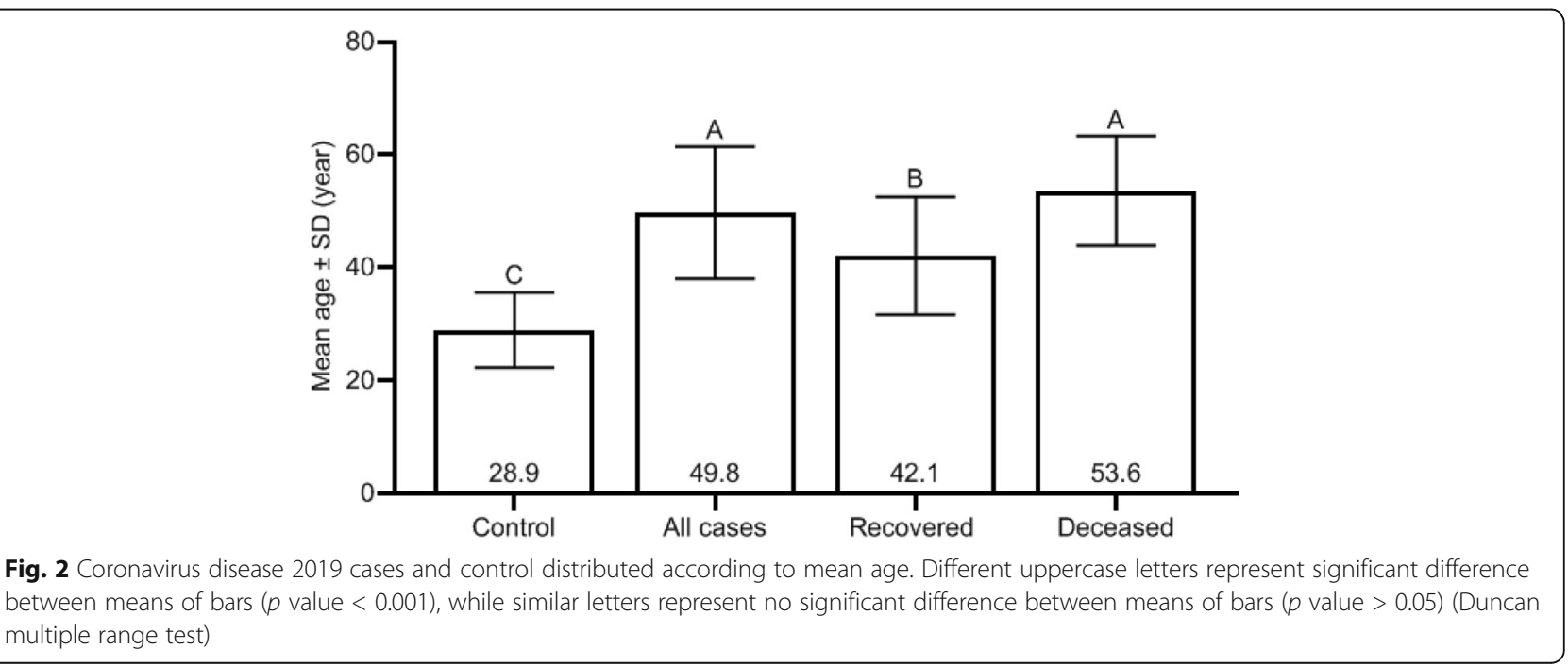


Table 1 Mean age of coronavirus disease 2019 cases and controls distributed according to gender

\begin{tabular}{lllll}
\hline Gender & \multicolumn{4}{l}{ Mean age \pm SD (year) } \\
\cline { 2 - 5 } & Controls & All cases & Recovered & Deceased \\
\hline Male & $29.3 \pm 6.9^{\mathrm{C}}$ & $49.7 \pm 12.3^{\mathrm{A}}$ & $41.7 \pm 11.1^{\mathrm{B}}$ & $54.0 \pm 8.8^{\mathrm{A}}$ \\
Female & $28.6 \pm 6.3^{\mathrm{C}}$ & $49.9 \pm 10.9^{\mathrm{A}}$ & $42.6 \pm 9.7^{\mathrm{B}}$ & $52.7 \pm 11.7^{\mathrm{A}}$ \\
$p$ value & 0.197 & 0.885 & 0.665 & 0.708
\end{tabular}

$S D$ standard deviation, $p$ least significant difference probability for comparison between males and females

Different superscript uppercase letters represent significant difference

between means in rows $(p$ value $<0.001)$, while similar letters represent no significant difference between means in rows ( $p$ value $>0.05$ ) (Duncan multiple range test)

increased risk of death in COVID-19 cases was associated with groups $\mathrm{A}, \mathrm{AB}, \mathrm{A}+\mathrm{AB}$, and $\mathrm{A}+\mathrm{B}+\mathrm{AB}(p c$ value $=0.007,0.042,0.007$, and 0.035 , respectively). The ORs these associations were 14.60 (95\% CI 2.85-74.88), 12.92 (95\% CI 2.11-79.29), 14.67 (95\% CI 2.98-72.33), and 9.67 (95\% CI 2.02-46.24), respectively (Table 4).

\section{Discussion}

Among the 300 COVID-19, males were more frequently encountered than females, especially in deceased cases. Previous studies also demonstrated that male cases outnumbered female cases, and males tended to have a more severe disease or at a critical status of illness. Further, males have been demonstrated to have 2.4 times risk of death compared to females [12-15]. There is no documented explanation for such gender preponderance of COVID-19 among males. However, it has been recently explored that such gender difference can be attributed to some comorbidities that indirectly increase the risk of infection or death among males. For instance, cardiovascular risk factors (heart disease, hypertension, and diabetes) and high-risk behaviors (social isolation, tobacco-smoking, alcohol use, and certain occupational exposures) are mostly associated with male gender [16]. Female sex hormones may also influence immune response regulation. Experimentally, it has been demonstrated that female mice were less prone to develop SARS-CoV infection than males. Further, increased mortality rate was increased among ovariectomized mice or female mice treated with estrogen receptor antagonist. It was concluded that estrogen receptor signaling may have a protective effects against SARS-CoV infection in females [17].

Age was a further risk factor for evolution of COVID19 , and the fifth decade may represent a critical age. Further, the results demonstrated that age can be considered as a death-associated risk factor. Most of Chinese data in this context agree that the infection was mostly observed in cases with advanced ages. Among 32,583 laboratory-confirmed COVID-19 cases from Wuhan (China), the median age of patients was 56.7 years, and elderly patients were at a higher risk of having severe or critical illness [13]. In a further Chinese study, 52 critically ill adult COVID-19 patients were explored. Their mean age was 59.7 years, and $61.5 \%$ of them died 28 days post-infection [14]. In a report from Korea, it has been found that age of COVID-19 patients showed M shape with two age peaks: 20s and 50s [18]. These findings might be expected because elderlies tend to have a higher prevalence of chronic diseases (for instance, cardiovascular diseases and diabetes) [19]. Further, reduced production of $\mathrm{B}$ and $\mathrm{T}$ cells in primary lymphoid organs and declined function of mature lymphocytes in secondary lymphoid tissues have been associated with aging [20]. These consequences will certainly increase the morbidity and mortality rates caused by viral and bacterial infections (including COVID-19) in elderlies.

Besides age and gender, $\mathrm{ABO}$ blood groups may also serve as susceptibility biomarkers for COVID-19. In this study, the overall distribution of the four phenotypes (A, $\mathrm{B}, \mathrm{AB}$, and $\mathrm{O}$ ) showed a significant variation between patients (all cases, recovered, and deceased) and controls. In terms of individual phenotype, each group of patients was presented with specific profile. Among all cases of COVID-19, logistic regression analysis depicted an OR of 3.10 (95\% CI 1.59-6.05) for group AB; therefore, such analysis suggested the susceptibility potential of this phenotype in the evolution COVID-19. Whereas, recovered cases were in favor of no significant association with $\mathrm{ABO}$ blood group phenotypes. On the contrary, deceased cases were markedly associated with group A $(\mathrm{OR}=14.60 ; 95 \%$ CI 2.85-74.88). However, the

Table 2 Phenotype frequencies of ABO blood groups among coronavirus disease 2019 cases and controls

\begin{tabular}{lllllll}
\hline Group & \multicolumn{2}{l}{ ABO blood group; $\boldsymbol{N}(\%)$} & & $\boldsymbol{p}$ value & p value \\
\cline { 2 - 5 } & A & B & AB & O & & \\
\hline Controls $(N=595)$ & $186(31.3)$ & $142(23.9)$ & $62(10.4)$ & $205(34.4)$ & \\
All cases $(N=300)$ & $86(28.7)$ & $80(26.7)$ & $59(19.6)$ & $75(25.0)$ & $2.3 \times 10^{-4}$ & $8.8 \times 10^{-4}$ \\
Recovered cases $(N=104)$ & $19(18.3)$ & $27(26.0)$ & $22(21.1)$ & $36(34.6)$ & 0.003 & 0.012 \\
Deceased cases $(N=37)$ & $20(54.1)$ & $3(8.1)$ & $12(32.4)$ & $2(5.4)$ & $3.7 \times 10^{-7}$ & $1.5 \times 10^{-6}$ \\
\hline
\end{tabular}

$p$ Pearson chi-squared test probability compared to controls, $p c$ Bonferroni corrected $p$ 
Table 3 Gene frequency of ABO blood group alleles among coronavirus disease 2019 cases and controls

\begin{tabular}{|c|c|c|c|c|c|c|}
\hline \multirow[t]{2}{*}{ Group } & \multicolumn{3}{|c|}{ Gene frequency (standard deviation) } & \multicolumn{3}{|c|}{ Hardy-Weinberg equilibrium } \\
\hline & $p[A]$ & $q[\mathrm{~B}]$ & $r[0]$ & Log likelihood & Chi-square & $p$ value \\
\hline Controls & $0.235(0.013)$ & $0.188(0.012)$ & $0.577(0.016)$ & -779.7 & 2.717 & 0.993 \\
\hline All cases & $0.274(0.020)$ & $0.261(0.019)$ & $0.465(0.023)$ & -418.4 & 11.197 & 0.001 \\
\hline Recovered cases & $0.212(0.030)$ & $0.261(0.033)$ & $0.526(0.038)$ & -148.4 & 16.245 & $<0.001$ \\
\hline Deceased cases & $0.601(0.072)$ & $0.218(0.051)$ & $0.181(0.068)$ & -40.1 & 1.756 & 0.185 \\
\hline
\end{tabular}

$p$ probability

three groups of patients shared a decreased frequency of group $\mathrm{O}$, and the protective potential of such phenotype against evolution of COVID-19 was suggested. Recent studies have also depicted the significance of group $\mathrm{O}$ in lowering COVID-19 risk [4, 5, 10]. However, the three groups of investigators demonstrated the significance of groups $\mathrm{A}, \mathrm{B}$, or $\mathrm{AB}$ in increasing the risk of infection. Zhao and colleagues demonstrated further that group A was associated with a higher risk of death [5]. Together, these findings suggest that $\mathrm{ABO}$ antigens may interplay with pathogenesis of COVID-19; however, the mechanism(s) by which these molecules confer susceptibility or protection is subjected to speculations.

It has been speculated that infectious agents may influence human genome evolution through natural selection of specific alleles that may prone the population to the risk of infection. Further, these agents often use glycosylated cell-surface receptors for their successful attachment, and by such pathway, ABO determinants may affect host-pathogen interactions through utilization of glycosylation [7]. In SARS-CoV infection, it has been demonstrated that $\mathrm{O}$-glycosylation plays a fundamental role in the virus pathogenesis [21]. Natural occurring anti-A and anti-B antibodies may also influence susceptibility to COVID-19 infection. In SARS-CoV infection, it has been hypothesized that these antibodies may decrease the rate of infection, and the degree of protection, may be influenced by the $\mathrm{ABO}$ antibody titer, secretor status, and incidence of group $\mathrm{O}$ in the population [9].

\section{Conclusions}

The findings of this study suggest the significance of ABO blood group system in susceptibility to or protection against COVID-19. In this context, group $A B$ may

Table 4 Genetic association of ABO blood group phenotypes with coronavirus disease 2019

\begin{tabular}{|c|c|c|c|c|c|}
\hline Comparison & Phenotype & OR & $95 \% \mathrm{Cl}$ & $p$ value & $p c$ value \\
\hline \multirow[t]{7}{*}{ All cases vs. controls } & $\mathrm{O}$ & Reference & & & \\
\hline & A & 1.46 & $0.84-2.56$ & 0.178 & 1.000 \\
\hline & B & 1.75 & $0.98-3.13$ & 0.059 & 0.413 \\
\hline & $A B$ & 3.10 & $1.59-6.05$ & 0.001 & 0.007 \\
\hline & $A+A B$ & 1.87 & $1.12-3.12$ & 0.016 & 0.112 \\
\hline & $B+A B$ & 2.16 & $1.28-3.63$ & 0.004 & 0.028 \\
\hline & $A+B+A B$ & 1.83 & $1.14-2.94$ & 0.013 & 0.091 \\
\hline \multirow[t]{7}{*}{ Recovered cases vs. controls } & $\mathrm{O}$ & Reference & & & \\
\hline & A & 0.76 & $0.38-1.49$ & 0.417 & 1.000 \\
\hline & B & 1.05 & $0.55-2.02$ & 0.877 & 1.000 \\
\hline & $A B$ & 1.91 & $0.91-4.00$ & 0.087 & 0.609 \\
\hline & $A+A B$ & 1.11 & $0.62-1.96$ & 0.731 & 1.000 \\
\hline & $B+A B$ & 1.32 & $0.75-2.3$ & 0.342 & 1.000 \\
\hline & $A+B+A B$ & 1.09 & $0.65-1.84$ & 0.750 & 1.000 \\
\hline \multirow[t]{7}{*}{ Deceased cases vs. controls } & O & Reference & & & \\
\hline & A & 14.60 & $2.85-74.88$ & 0.001 & 0.007 \\
\hline & $B$ & 2.07 & $0.29-14.78$ & 0.469 & 0.609 \\
\hline & $A B$ & 12.92 & $2.11-79.29$ & 0.006 & 0.042 \\
\hline & $A+A B$ & 14.67 & $2.98-72.33$ & 0.001 & 0.007 \\
\hline & $B+A B$ & 6.30 & $1.21-32.81$ & 0.029 & 0.203 \\
\hline & $A+B+A B$ & 9.67 & $2.02-46.24$ & 0.005 & 0.035 \\
\hline
\end{tabular}

$O R$ odds ratio, $\mathrm{Cl}$ confidence interval, $p$ logistic regression analysis probability adjusted for age and gender, $p c$ Bonferroni corrected $p$ 
be a susceptibility biomarker for the infection, while group A may be associated with a higher risk of death. However, the present study was limited by the sample size especially in deceased cases. Thus, the obtained results motivated us to plan for a larger-scaled study based on a larger sample size of patients from Baghdad and other Iraqi cities.

\section{Abbreviations}

Cl: Confidence interval; COVID-19: Coronavirus disease 19; HWE: HardyWeinberg equilibrium; LSD: Least significant difference; OR: Odds ratio; p: Probability; pc: Bonferroni corrected p; SARS-CoV-2: Severe acute respiratory syndrome coronavirus 2; SD: Standard deviation

\section{Acknowledgements}

The authors appreciate the cooperation of the medical staff at hospitals in Baghdad.

\section{Authors' contributions}

AHA managed data, carried out statistical analyses, and wrote the manuscript. RHA, RHM, MHA, AJA, and MYA contributed to data handling, writing and revising the manuscript. All authors read and approved the final manuscript.

\section{Funding}

This research did not receive any specific grant from funding agencies in the public, commercial, or not-for-profit sectors.

\section{Availability of data and materials}

The datasets used and/or analyzed during the current study are available from the corresponding author on reasonable request.

\section{Ethics approval and consent to participate}

The participants provided their written informed consent to be included in the study. The study protocol was approved by the Ethics Committee at the Iraqi Ministry of Health and Environment (N268 on 31 May 2020).

\section{Consent for publication}

Not applicable.

\section{Competing interests}

The authors declare that they have no competing interests.

\section{Author details}

${ }^{1}$ Tropical-Biological Research Unit, College of Science, University of Baghdad, Baghdad, Iraq. ${ }^{2}$ College of Biotechnology, Al-Nahrain University, Baghdad, Iraq. ${ }^{3}$ College of Agriculture, University of Basrah, Basrah, Iraq. ${ }^{4}$ Biotechnology Department, College of Science, University of Baghdad, Baghdad, Iraq. ${ }^{5}$ Basrah Health Office, Ministry of Health and Environment, Baghdad, Iraq.

Received: 1 August 2020 Accepted: 4 September 2020

Published online: 11 September 2020

\section{References}

1. Gorbalenya AE, Baker SC, Baric RS, de Groot RJ, Drosten C, Gulyaeva AA et al (2020) The species severe acute respiratory syndrome-related coronavirus: classifying 2019-nCoV and naming it SARS-CoV-2. Nat Microbiol 5:536-544 https://doi.org/10.1038/s41564-020-0695-z

2. Roser M, Ritchie H, Ortiz-Ospina E, Hasell J (2020) Coronavirus Pandemic (COVID-19). Our World Data https://ourworldindata.org/coronavirus (

3. Yang L, Liu J, Zhang R, Li M, Li Z, Zhou X et al (2020) Epidemiological and clinical features of 200 hospitalized patients with corona virus disease 2019 outside Wuhan China: A descriptive study. J Clin Virol 129:104475 https:// doi.org/10.1016/j.jcv.2020.104475

4. Wu Y, Feng Z, Li P, Yu Q (2020) Relationship between ABO blood group distribution and clinical characteristics in patients with COVID-19. Clin Chim Acta 509:220-223 https://doi.org/10.1016/j.cca.2020.06.026
5. Zhao J, Yang Y, Huang H-P, Li D, Gu D-F, Lu X-F, et al. Relationship between the ABO Blood Group and the COVID-19 Susceptibility. MedRxiv 2020; [Epub ahea:2020.03.11.20031096. https://doi.org/10.1101/2020.03.11.20031096.

6. Yamamoto F (2000) Molecular genetics of ABO. Vox Sang 78(Suppl 2):91103

7. Franchini $M$, Bonfanti C (2015) Evolutionary aspects of $A B O$ blood group in humans. Clin Chim Acta 444:66-71 https://doi.org/10.1016/j.cca.2015.02.016

8. Bodmer W (2015) Genetic characterization of human populations: From abo to a genetic map of the british people. Genetics 199:267-279 https://doi. org/10.1534/genetics.114.173062

9. Cooling $L$ (2015) Blood groups in infection and host susceptibility. Clin Microbiol Rev 28:801-870 https://doi.org/10.1128/CMR.00109-14

10. Latz CA, DeCarlo C, Boitano L, Png CYM, Patell R, Conrad MF et al (2020) Blood type and outcomes in patients with COVID-19. Ann Hematol https:// doi.org/10.1007/s00277-020-04169-1

11. Cheng Y, Cheng G, Chui CH, Lau FY, Chan PKS, Ng MHL et al (2005) ABO blood group and susceptibility to severe acute respiratory syndrome. J Am Med Assoc 293:1450-1451 https://doi.org/10.1001/jama.293.12.1450-c

12. Ge H, Wang X, Yuan X, Xiao G, Wang C, Deng T et al (2020) The epidemiology and clinical information about COVID-19. Eur J Clin Microbiol Infect Dis 39:1011-1019 https://doi.org/10.1007/s10096-020-03874-z

13. Pan A, Liu L, Wang C, Guo H, Hao X, Wang Q et al (2020) Association of Public Health Interventions with the Epidemiology of the COVID-19 Outbreak in Wuhan, China. JAMA - J Am Med Assoc 323:1915-1923 https:// doi.org/10.1001/jama.2020.6130

14. Yang $X, Y u$ Y, Xu J, Shu H, Xia J, Liu H et al (2020) Clinical course and outcomes of critically ill patients with SARS-CoV-2 pneumonia in Wuhan, China: a single-centered, retrospective, observational study. Lancet Respir Med 8:475-481 https://doi.org/10.1016/S2213-2600(20)30079-5

15. Jin J-M, Bai P, He W, Wu F, Liu X-F, Han D-M et al (2020) Gender Differences in Patients With COVID-19: Focus on Severity and Mortality. Front Public Heal 8:152 https://doi.org/10.3389/fpubh.2020.00152

16. Sharma G, Volgman AS, Michos ED (2020) Sex Differences in Mortality From COVID-19 Pandemic. JACC Case Reports https://doi.org/10.1016/j.jaccas. 2020.04.027

17. Channappanavar R, Fett C, Mack M, Ten Eyck PP, Meyerholz DK, Perlman S (2017) Sex-Based Differences in Susceptibility to Severe Acute Respiratory Syndrome Coronavirus Infection. J Immunol 198:4046-4053 https://doi.org/ 10.4049/jimmunol.1601896

18. Korean Society of Infectious Diseases, Korean Society of Pediatric Infectious Diseases, Korean Society of Epidemiology, Korean Society for Antimicrobial Therapy, Korean Society for Healthcare-associated Infection Control and Prevention, and Korea Centers for Disease Control and Prevention. Report on the epidemiological features of coronavirus disease 2019 (covid-19) outbreak in the republic of korea from january 19 to march 2, 2020. J Korean Med Sci. 2020;35(10). doi:https://doi.org/10.3346/jkms.2020.35.e112

19. Maresova P, Javanmardi E, Barakovic S, Barakovic Husic J, Tomsone S, Krejcar $O$ et al (2019) Consequences of chronic diseases and other limitations associated with old age - A scoping review. BMC Public Health 19:1431 https://doi.org/10.1186/s12889-019-7762-5

20. Montecino-Rodriguez E, Berent-Maoz B, Dorshkind K (2013) Causes, consequences, and reversal of immune system aging. J Clin Invest 123:958965 https://doi.org/10.1172/JCl64096

21. Oostra M, de Haan CAM, de Groot RJ, Rottier PJM (2006) Glycosylation of the severe acute respiratory syndrome coronavirus triple-spanning membrane proteins 3a and M. J Virol 80:2326-2336 https://doi.org/10.1128/ jvi.80.5.2326-2336.2006

\section{Publisher's Note}

Springer Nature remains neutral with regard to jurisdictional claims in published maps and institutional affiliations. 